\title{
O QUE TORNA A REPRESENTAÇÃO DEMOCRÁTICA?*
}

Nadia Urbinati

Este trabalho é uma síntese do primeiro capítulo do meu livro Democracia Representativa: Princípios e Genealogia (Representative Democracy: Principles and Genealogy), que será publicado pela University of Chicago Press. Para auxiliar o leitor, irei esboçar os argumentos principais do livro.

Na obra, investigo as condições que tornam a representação democrática um modo de participação política que possa ativar uma variedade de formas de controle e supervisão dos cidadãos. Argumento que a democracia representativa é uma forma de governo original, que não é idêntica à democracia eleitoral. Ao invés de usar uma estratégia polêmica, procuro iluminar as suposições não questionadas quanto à proximidade e presença física que apóiam a idéia de que a democracia direta é sempre a forma política mais democrática, e a representação, um recurso ou uma alternativa second best. Valho-me dos trabalhos seminais de Hanna Pitkin e Bernard Manin para demonstrar que a represen-

\footnotetext{
* Apresentado no Encontro Anual da American Political Science Association (Apsa), Washington (EUA), setembro de 2005. Tradução de Mauro Soares.
} 
tação política é um processo circular (suscetível ao atrito) entre as instituições estatais e as práticas sociais. Como tal, a democracia representativa não é nem aristocrática nem um substituto imperfeito para a democracia direta, mas um modo de a democracia recriar constantemente a si mesma e se aprimorar. A soberania popular, entendida como um princípio regulador "como se" guiando a ação e o juízo políticos dos cidadãos, é um motor central para a democratização da representação.

No livro, utilizo uma abordagem genealógica para ilustrar essa teoria da democracia representativa. De fato, estudiosos das instituições políticas estão de acordo com que os princípios centrais do governo representativo foram estabelecidos no século dezoito com o propósito de refrear a democracia e construir um governo limitado e, desta forma, responsável. O quadro que desenho (por meio de um exame crítico das teorias da representação de

192 Rousseau, Kant, Sieyès, Paine e Condorcet) mostra que as coisas são um pouco mais complicadas. A idéia do governo representativo como intrinsecamente singular produziu duas escolas distintas de pensamento que podem ser referidas, respectivamente, como um modelo eleitoral de democracia e um modelo representativo. A primeira endossava uma visão da representação que combinou elitismo nas instituições políticas (o único local tanto da deliberação bem como do voto) e legitimação popular (localizada na votação através da eleição), na qual o primeiro consistiria no domínio da competência e a última no domínio do consentimento. Nesta visão, a representação se funda no princípio da divisão do trabalho e em uma seleção funcional de expertise. A segunda escola de pensamento era explicitamente democrática e visava evitar a concentração da fonte de legitimação nas instituições estatais e a redução do consentimento popular a um ato de autorização. Nesta visão, a representação se funda na teoria do consentimento, que 
vê a eleição como a expressão do direito de participar em algum nível da produção das leis, não como um método de transferência das preferências idiossincráticas das pessoas a profissionais políticos selecionados. Desde o século dezoito, teóricos da democracia representativa (a saber, Paine e Condorcet) propuseram situar a representação dentro de um misto complexo de deliberação e voto, autorização formal e influência informal, que envolvia tanto representantes quanto cidadãos. Em vez de um esquema de delegação da soberania, eles viam a representação como um processo político que conecta sociedade e instituições.

Uma teoria da democracia representativa envolve uma revisão da concepção moderna de soberania popular que conteste o monopólio da vontade na definição e na prática da liberdade política. Ela marca o fim da política do sim ou não e o início da política como uma arena de opiniões contestáveis e decisões sujeitas à revisão a qualquer tempo. Isso amplifica o significado da própria presença política, porque faz da vocalização sua manifestação mais ativa e consoante e do juízo acerca das leis e políticas justas e injustas seu conteúdo. Pode-se dizer que a representação política provoca a disseminação da presença do soberano e sua transformação em uma tarefa contínua e regulada de contestação e reconstrução da legitimidade. Portanto, embora a autorização eleitoral seja essencial para se determinar os limites e a responsabilidade do poder político, ela não nos diz muito a respeito da verdadeira natureza da política representativa em uma sociedade democrática. As eleições "engendram" a representação, mas não "engendram" os representantes. No mínimo, elas produzem um governo responsável e limitado, mas não um governo representativo.

Isso me leva a argumentar que a representação ativa um tipo de unificação política que não pode nem ser definida nos termos de um acordo contratual entre eleitores e eleitos, nem decomposta em um sistema de competição que 
aponte aqueles que deverão pronunciar o interesse geral de todos. Um representante político é único não porque substitui o soberano na aprovação das leis, mas precisamente porque ele não é um substituto para o soberano ausente (a parte que substitui o todo), uma vez que ele precisa ser constantemente recriado e estar dinamicamente em harmonia com a sociedade para aprovar leis legítimas. Com base nisso, é correto afirmar que a democratização e o processo representativo compartilham uma genealogia e não são antitéticos. O juízo e a opinião são sedes da soberania tanto quanto a vontade, se admitirmos a soberania como correspondendo a uma temporalidade ininterrupta e a influência incalculável dos princípios e ideais básicos concernentes ao interesse geral, que transcendem os atos de decisão e eleição. Essa reflexão me leva a sustentar que a representação estimula um ganho de política em relação ao ato sancionador pelo qual os cidadãos

194 soberanos ratificam e recapitulam, com regularidade cíclica, as ações e promessas de candidatos e representantes. Representatividade e defesa são as expressões desse ganho e marcam o vínculo inevitável, ativado pelo processo eleitoral, entre o lado de dentro e o lado de fora das instituições legislativas.

A representação democrática pressupõe, notadamente, uma revisão das noções tanto de representação quanto de soberania. Neste artigo, irei me concentrar na primeira e sustentar três principais argumentos: o de que a representação pertence à história e à prática da democratização; o de que diferentes teorias de representação são possíveis, dependendo da relação entre Estado e sociedade civil; e o de que esta relação chama a atenção para o papel da ideologia e do partidarismo na política, um aspecto que a teoria política contemporânea deixa de apreciar com sua profundamente arraigada abordagem racionalista da deliberação. 


\section{Democracia e representação}

O trabalho cuidadoso de Mark A. Kishlansky sobre o nascimento do processo eleitoral na Inglaterra do século dezessete revelou um liame cronológico e funcional entre três fenômenos políticos: a adoção do método eleitoral para se designar os legisladores; a transformação dos eleitos, de delegados em representantes; e a emergência das alianças partidárias ou ideológicas entre os cidadãos. Embora as eleições tenham sido consideradas uma instituição aristocrática desde Aristóteles, nos Estados modernos o processo eleitoral estimulou dois movimentos que se tornaram cruciais para o subseqüente processo de democratização. Por um lado, ele desencadeou uma separação entre sociedade e Estado ou, melhor dizendo, uma transição de relações simbióticas entre os delegados e suas comunidades para formas de unificação que eram totalmente simbólicas e construídas politicamente. Por outro, a dissociação dos candidatos de suas posições ou classes sociais destacou o papel das idéias na política, ou, como preferiria dizer, o propósito idealizador do processo de representação. Como resultado, a representação não pode ser reduzida nem a um contrato (de delegação) firmado através das eleições nem à nomeação de legisladores como substitutos do soberano ausente, porque sua natureza consiste em ser constantemente recriada e dinamicamente ligada à sociedade. Em suma, a história moderna sugere que a genealogia da democratização começou com o processo representativo. A democratização do poder estatal e o poder unificador das idéias e movimentos políticos levados a cabo pela representação foram interconectados e mutuamente reforçadores ${ }^{1}$.

A análise de Kishlansky sugere que abordemos as eleições e a representação em termos da relação entre o Estado

1. Mark A. Kishlansky(1986: 21). 
(o governo) e a sociedade civil. Embora a estrutura eleitoral da representação não tenha mudado muito em dois séculos a despeito da extensão do sufrágio, os teóricos não deveriam fazer vista grossa às mudanças cruciais que a transformação democrática engendrou no funcionamento e significado das instituições representativas ${ }^{2}$. A emergência do "povo" (os cidadãos) como um agente político ativo não se limitou a meramente renovar instituições e categorias antigas. No momento em que as eleições se tornaram um requerimento solene e indispensável de legitimidade política e formação de magistraturas, Estado e sociedade não puderam mais ser desligados e o traçado das fronteiras separando - e conectando - suas esferas de ação tornou-se uma questão persistente de reajuste e negociação. A representação espelha esta tensão. Pode-se dizer que ela reflete não simplesmente idéias e opiniões, mas idéias e opiniões a respeito das visões dos cidadãos acerca da relação

196 entre a sociedade e o Estado. Qualquer reivindicação que os cidadãos tragam para a arena política e queiram tornar um tema de representação é invariavelmente um reflexo da luta para a redefinição das fronteiras entre as suas condições sociais e a legislação.

\section{Três teorias da representação}

Três teorias da representação emergem quando olhamos como o governo representativo funcionou ao longo de seus duzentos anos de história, do parlamentarismo liberal dos primórdios até sua crise e, finalmente, sua transformação democrática, após a Segunda Guerra Mundial. Podemos

\footnotetext{
2. Para uma análise em estudo de caso das mudanças estruturais ocorridas ao longo da democratização do sistema eleitoral (extensão do direito de voto e voto secreto) veja-se Robert A. Dahl (s.d.: 1-50). Sobre a estrutura inalterada do governo representativo a partir de sua instauração constitucional no século dezoito: Bernard Manin (1997: 3).
} 
dizer que a representação tem sido interpretada alternativamente de acordo com três perspectivas: jurídica, institucional e política. Elas pressupõem concepções específicas de soberania e política e, conseqüentemente, relações entre Estado e sociedade específicas. Todas elas podem também ser usadas para se definir democracia (respectivamente, direta, eleitoral e representativa). Contudo, apenas a última faz da representação uma instituição consonante com uma sociedade democrática e pluralista ${ }^{3}$.

As teorias jurídica e institucional estão interconectadas bem de perto. Elas são ambas baseadas em uma analogia entre Estado e Pessoa e em uma concepção voluntarista de soberania, e são expressas em uma linguagem formalista. A teoria jurídica é a mais antiga e requer mais atenção, pois cunhou o modelo para a institucional, a qual foi seu rebento. Ela pré-datou a concepção moderna de soberania estatal e a nomeação eleitoral de legisladores. É denominada jurídica porque trata a representação como um contrato privado de comissão (concessão de "autorização para realizar uma ação por pessoa ou pessoas que devem ser elas mesmas detentoras do direito de realizar essa dada ação" ${ }^{4}$ ). Delegação (instruções vinculativas) e alienação (incumbência ilimitada) têm sido tradicionalmente os dois pólos extremos desse modelo, a primeira simbolizada por Rousseau e a última por Hobbes, e além dele, Sieyès e Burke (embora o primeiro não tenha teorizado um "protetorado" representativo e o último não tenha assentado a representação sobre uma base contra-

3. Estas três concepções são identificáveis nos escritos dos autores que optei por analisar neste trabalho, marcadamente Rousseau, Sieyes e Condorcet.

4. Quentin Skinner (2002, vol. 3: 185). A teoria jurídica era consistente com a função consultiva dos delegados no parlamento pré-eleitoral e tornou-se relevante em funções administrativas modernas (por exemplo, em comunidades locais e em corporações); M. V. Clarke (1964: 283-288). 
tual $)^{5}$. O modelo jurídico configura a relação entre representado e representante conforme as linhas de uma lógica individualista e não-política, na medida em que supõe que os eleitores julgam as qualidades pessoais dos candidatos, ao invés de suas idéias políticas e projetos. Desta forma, a representação não é e não pode ser um processo, nem pode ser uma matéria política (que implique, por exemplo, uma demanda por representatividade ou representação justa), de início pela simples razão de que, nas palavras de Pitkin, a representação é "por definição" "qualquer coisa feita após o tipo correto de autorização e dentro de seus limites" ${ }^{6}$. Como Anthony Downs candidamente reconheceu, ao comentar os efeitos da aplicação do modelo privado de representação que ele endossava à democracia, "não há nada para os representantes representarem" .

A teoria jurídica da representação reúne as matérias do poder estatal e da legitimidade dentro da lógica do par 198 presença/ausência (do soberano) e descola a representação da defesa e da representatividade, as duas manifestações políticas - conforme logo explicarei - que provêm de sua

\footnotetext{
5. Muito embora o modelo moderno de autorização teve Hobbes como seu primeiro teórico, seria incorreto classificar a concepção de Hobbes como a de um governo representativo, pois, uma vez autorizado, o seu soberano pode agir como quiser. Uma vez que Hobbes não prevê eleições após o ato primeiro de autorização, a obrigação do soberano de agir com vistas ao bem comum dos súditos fica inteiramente à sua discricionariedade. Pode-se objetar que o interesse - o interesse do governante em preservar seu poder - pode, não obstante, atuar como uma força normativa de responsabilidade e ir ao encontro dos interesses da sociedade por paz e estabilidade. Esta não é, contudo, uma relação de representação política, que exige direta submissão a eleições periódicas e regulares, pois esta não se apóia sobre o juízo discricionário do governante.

6. Pitkin sustenta que essa teoria faz a representação parecer uma "caixa preta", algo que ela mesma não consegue compreender nem definir. "Não pode haver algo como representar bem ou mal... Não existem coisas como a atividade de representação ou os deveres de um representante" (1967: 39). John Locke não é exceção, pois, ainda que os dois contratos que teorizou permitiam ao indivíduo reter seu poder básico de julgamento, as eleições (o segundo contrato), contudo, são única e essencialmente um meio para a criação de instituições e não representação do povo.
}

7. Anthony Downs (1957: 89). 
relação inevitável com a sociedade e a atividade política dos cidadãos. Com Hobbes, seu primeiro intérprete moderno, esta abordagem evoluiu para uma tecnologia de formatação de instituições que se tornou enormemente influente tanto para os teóricos do governo representativo (Sieyès, certamente) quanto para seus críticos. Durante a crise do parlamentarismo, por exemplo, no começo do século vinte, Carl Schmitt recuperou a função construtivista da representação concebida por Hobbes e Sieyès e a usou para tornar o ausente presente ou reconstruir a unidade orgânica do Volk acima do (e contrária ao) pluralismo dos interesses sociais, através da personificação do soberano (no líder ou führer). Seu objetivo era um Estado unificado mais fortemente do que era possível por meio do compromisso parlamentar entre interesses ou do "governo por discussão" o caso de Schmitt é um exemplo útil da incompatibilidade entre a representação como uma técnica de unidade (mística) da comunidade e a representação política.

A teoria jurídica da representação abriu as portas para uma justificação funcionalista da representação e dos direitos políticos, da cidadania e dos processos de tomada de decisão. Sua fundamentação tornou-se a coluna vertebral do governo representativo liberal e, mais tarde, da democracia eleitoral. Ela é baseada em um dualismo bem definido entre Estado e sociedade; faz da representação uma instituição centrada rigorosamente no Estado, cuja relação com a sociedade é deixada ao juízo do representante (tutor); e restringe a participação popular a um mínimo procedimental (eleições como a nomeação de magistrados).

8. A origem da idéia de representação foi a Bula Papal Unam Sanctam, do Papa Bonifácio VIII (1302). O corpus mysticum Christi era a Igreja unida espiritualmente por Cristo através de seu vigário, o Papa, que comandava a Igreja visível dos fiéis; Ernst Kantorowicz (1957: 167-179). A respeito da secularização da unidade mística na unidade do Estado sob a pessoa do Líder (führer), sustentada por Schmitt, ver Ellen Kennedy (2004: 64-81). 
Em resumo, a perspectiva centrada no Estado, sugerida pela teoria jurídica, prefigura dois cenários possíveis. De um lado, como argumentava Rousseau, a representação não tem lugar no discurso de legitimação política pela razão óbvia de que significa transferir o poder de autorização do uso da força (o poder soberano) da comunidade como um todo para sua(s) parte(s). De outro, como argumentou Sieyès, a representação pode ser uma estratégia de edificação de instituições na condição de que seja dada aos súditos apenas a tarefa de selecionar os legisladores. Também neste caso a soberania é essencialmente voluntarista e sua vontade restrita à vontade eleitoral, com o resultado (e o propósito consciente) de que a nação soberana fala apenas através da voz dos eleitos. Nesta conta, a soberania parlamentar pode ser vista, paradoxalmente, como uma transmutação eleitoral da doutrina da vontade geral de Rousseau, uma vez que, transferida para a Nação representada, aquela vontade se 200 torna uma estratégia para se "bloquear o caminho para a democracia”.

Tanto a teoria jurídica como a teoria institucional da representação assumem que o Estado (e a representação como seu mecanismo produtivo e reprodutivo) deve transcender a sociedade de modo que se assegure o Estado de Direito, e que as pessoas devem encobrir suas identidades sociais e concretas para tornar os mandatários agentes imparciais de decisão. Elas supõem que a identidade jurídica do eleitor/autorizador é vazia, abstrata e anônima, sua função consistindo em "nomear" políticos profissionais que tomem decisões às quais os eleitores se submetem voluntariamente. Assim, “o que encontramos no sistema denominado representativo é que ele não é um sistema de representação do povo e da vontade da nação, mas um sistema de

9. Marcel De la Bigne de Villeneuve (1929-1931, vol. 2: 32). 
organização do povo e da vontade da nação"10. A suposição subjacente à separação entre "o homem" e "o cidadão", a qual Karl Marx famosamente condenou por sua hipocrisia asinina, era a de que a esfera política deve ser independente da esfera social (e em particular dos interesses econômicos e das crenças religiosas) para que sejam obtidas a igualdade legal e a organização impessoal do Estado. Esta é a premissa axiológica comum a ambas as teorias da representação e a conseqüência lógica de sua abordagem construtivista da soberania ${ }^{11}$. Elas emergiram e foram moldadas antes da transformação democrática da sociedade e do Estado e permaneceram essencialmente impermeáveis a ela.

\section{Representação política}

A terceira teoria rompe com estes dois modelos. Ela cria uma categoria inteiramente nova na medida em que concebe a representação dinamicamente, ao invés de estaticamente: a representação não tem que fazer uma entidade preexistente - p. ex. a unidade do Estado ou do povo ou da nação - visível; diferentemente, ela é uma forma de existência política criada pelos próprios atores (o eleitorado e o representante). Esta teoria faz jus à especificidade da representação política em relação a todas as outras formas de mandato e em particular ao esquema privado de autorização. A representação não pertence apenas aos agentes ou instituições governamentais, mas designa uma forma de processo político que é estruturada nos termos da circularidade entre as instituições e a sociedade, e não é confinada à deliberação e decisão na assembléia. "É tarefa dos represen-

10. Raymond Carré de Malberg (1922, vol. 1: 231).

11. Neste caso, a representação perde todo o seu caráter político e é identificada com o ato de instituição da função de um orgão; a separação entre o cargo e o agente ou a formação do Estado no sentido weberiano qualifica esta concepção como uma teoria do funcionalismo. 
tantes populares, portanto, coordenar e criticar. A unidade necessária não se segue logicamente da unidade daquele que representa, como Hobbes sustentaria, mas deve ser criada e constantemente recriada através de um processo político de atividade dinâmica"12. Sua gradual consolidação durante o século vinte, com a adoção do sufrágio universal (embora uma formulação anterior possa ser encontrada na argumentação de John Stuart Mill pela representação proporcional), reflete a transformação democrática tanto do Estado quanto da sociedade e o crescimento do mundo complexo da opinião pública e da vida associativa, que dão ao juízo político um peso que ele nunca antes teve. Esboçada por Carl J. Friedrich em um capítulo que é uma obra-dearte de clareza, devemos sua reformulação de orientação mais democrática a Hannah Pitkin: "a representação aqui significa agir no interesse dos representados, de uma maneira responsiva a eles"13.

202 A teoria política da representação argumenta que, em um governo que deriva sua legitimidade de eleições livres e regulares, a ativação de uma corrente comunicativa entre a sociedade política e a civil é essencial e constitutiva, não apenas inevitável. Invertendo a máxima sustentada pelas duas teorias prévias, ela argumenta que a generalidade da lei e os critérios de imparcialidade derivados da cidadania nem deveriam nem necessitam ser realizados às custas da visibilidade política do "homem" (leia-se, a identidade "social" como distinta de e oposta à identidade "política"). As múltiplas fontes de informação e as variadas formas de comunicação e influência que os cidadãos ativam através da mídia, movimentos sociais e partidos políticos dão o tom da representação em uma sociedade democrática, ao tornar

12. Carl J. Friedrich (1963: 273); também Ernst-Wolfgang Böckenförde (1991, caps. 6-7).

13. Pitkin, (1967: 209); Friedrich (1963, chap. 17). 
o social político. Vontade e juízo, a presença física imediata (o direito ao voto) e uma presença idealizada mediada (o direito à livre expressão e à livre associação) estão inextricavelmente entrelaçados em uma sociedade que é ela mesma uma confutação viva do dualismo entre a política da presença e a política das idéias, uma vez que toda presença é um artefato do discurso.

A representação política não elimina o centro de gravidade da sociedade democrática (o povo), ao mesmo tempo em que despreza a idéia de que os eleitores em vez dos cidadãos ocupem este centro, de que o ato de autorização seja mais importante do que o processo de autorização.

\section{Continuidade, ruptura e o poder negativo}

Quando o constitucionalismo liberal se estabeleceu como um projeto consciente de engenharia do Estado no século dezoito, os líderes e teóricos políticos pensavam que o espaço dual dos cidadãos e instituições representativas produzido pelas eleições era o sine qua non da legiferação imparcial e competente, porque protegia o arranjo deliberativo tanto das paixões tirânicas da maioria quanto dos interesses particulares das facções. Esta crença permeou os escritos de autores tão diversos quanto Madison e Burke, que promoveram uma versão elitista da razão pública de Rousseau, ao fazer dela a realização de cidadãos selecionados e virtuosos. O problema, contudo, é que, uma vez que os líderes e as instituições, ao invés de imparcialmente desvinculados das influências sociais, são vulneráveis a elas, este dualismo não funcionou e não funciona como pretendido. Somente se os representantes fossem imparciais, virtuosos e competentes motu proprio poderia o insulamento de suas vontades em relação aos cidadãos solucionar o problema da parcialidade e da corrupção. Se este fosse o caso, entretanto, as eleições não teriam sentido.

Todavia, a escolha da eleição como um método de seleção prova duas coisas: primeiro, nem o povo nem o governo 
podem contar com a sorte para obter bons legisladores; e, segundo, não existe algo como uma aristocracia naturalmente selecionada e auto-referencial. Ainda que as eleições sejam um método de controle formalmente limitado porque post-factum e apenas indiretamente antecipatório, elas comprovam o fato de que em uma democracia os representantes não devem e jamais podem ser insulados da sociedade. Falando historicamente, esta é a razão pela qual as eleições se tornaram sinônimo de democracia e a exigência de instituições representativas sinônimo da reivindicação popular por soberania. Fazendo uma retificação à concepção minimalista de democracia, eu diria que a competição eleitoral tem duas virtudes de destaque, não uma: ao passo que ela ensina os cidadãos a se livrarem dos governos pacificamente, ela também os faz participar do jogo de tornar a si mesmos livres dos governos.

É por essa razão que o direito a voto faz mais do que 204 somente "evitar a guerra civil" 14 . O direito a voto engendra uma vida política rica, que promove agendas políticas concorrentes e condiciona a vontade dos legisladores de uma forma constante, não apenas no dia da eleição. Ele encoraja o desenvolvimento amplo de formas extra-eleitorais de ação política, embora sem a garantia de que a influência política será distribuída igualmente e se tornará autorizada. Além do mais, ele realça o paradoxo da visão instrumentalista da representação, a qual, por um lado, refere-se à opinião do povo como a fonte de legitimidade e, por outro, sustenta que os representantes tomam decisões boas e racionais conforme se protegem de uma "opinião popular sempre manipulável"15.

O paradoxo dessa abordagem não-política (já que guiada pela competência) da política é que, a despeito de ela se 
arrogar ser a marca registrada das liberdades civis e econômicas e do constitucionalismo, ela abre caminho para uma teoria das instituições que é tão insensível à representação quanto a teoria de Rousseau do governo direto. Ela supõe que o representante deva ser surdo à opinião pública para tomar boas decisões. No centro desse paradoxo está a visão formalista, geralmente não revelada, da participação dos cidadãos como veredicto eleitoral do soberano (autorização aos magistrados) e uma visão estreita da deliberação democrática como um processo que envolve exclusivamente os eleitos e refere-se a decisões autorizadas. O resultado é uma "visão incompleta e distorcida" do que são os representantes e de como eles devem agir ${ }^{16}$. A conclusão previsível é a de que a eleição funciona para conferir poder a uma classe profissional que delibera acima das cabeças dos cidadãos, cuja única função é "aceitar" ou "recusar" seus líderes e nunca molestálos enquanto eles tocam seus negócios, já que "devem compreender que, uma vez que tenham elegido um indivíduo, a atuação política é problema deste, não deles"17.

Importantes esforços têm sido feitos para se estimular uma interpretação não-formalista. De fato, desde seus primórdios constitucionais, o governo representativo pertenceu a uma família complexa e plural cujo ramo democrático não era propriedade exclusiva daqueles que advogavam por participação ao invés de representação. Como sustenta meu livro, os revolucionários americanos e franceses do século dezoito usavam dois termos distintos para denotar suas iniciativas inovadoras: governo representativo e democracia representativa. Ainda que ambos os termos tenham sido usados por vezes

16. Pitkin (1967: 54). Elster definiu o discurso aos eleitores de Bristol, de Burke, como "a mais famosa exposição de razões para a democracia deliberativa", embora Burke estivesse propondo "democracia" para os poucos, ou traçando um modelo de aristocracia deliberativa ao invés de democracia deliberativa(cf Elster, 1998: 3).

17. Joseph A. Schumpeter (1962: 295). 
como sinônimos, os líderes políticos mais perspicazes estavam conscientes das diferenças. Por exemplo, Sieyès nunca usou o último, mas Condorcet o fez, julgando que o cidadão soberano devesse ter os direitos e os "meios legais" para ser ativo quando quer que ele/ela o achasse "útil ou necessário". Designar representantes não era o único meio de se participar ou a única função relacionada ao droit de cité.

Retomando a intuição de Condorcet, eu argumento que a especificidade e a singularidade da democracia moderna estão necessariamente baseadas, ainda que a isso não se limitem, no lançamento das "pedras de papel” por intermédio do voto ${ }^{18}$. Elas residem na circularidade que as eleições criam entre o Estado e a sociedade e no continuum do processo de tomada de decisões que liga os cidadãos à assembléia legislativa. Esta é também a fundamentação da teoria discursiva da soberania popular, uma importante contribuição à interpretação democrática da represen206 tação. A teoria do discurso, contudo, fornece apenas um retrato parcial do processo político de representação, pois, ao passo que enfatiza a comunicação (circularidade) como "a força socialmente integradora" que unifica os momentos parlamentar e extraparlamentar, ela não presta suficiente atenção aos momentos de ruptura daquela comunicação, momentos de circuito que trazem à baila, à revelia, a contribuição da representatividade à legitimação democrática da representação ${ }^{19}$.

Em um estilo hegeliano, o modelo de mediação de Jürgen Habermas explica bem melhor a relação orgânica entre o Estado e a sociedade do que a crise dessa relação, quando a continuidade entre os representantes e os cidadãos é interrompida e os últimos ficam propensos a gerar formas

18. Empresto a expressão de Engels, através de Przeworski "Minimalist conception of democracy" (1998: 49).

19. Habermas (1996: 299). 
extraparlamentares de auto-representação; quando formas de espontaneidade política (novos movimentos) penetram a cena política e enriquecem a pluralidade de vozes. $\mathrm{O}$ fenômeno que requer nossa atenção encontra-se entre o estado de normalidade orgânica e o evento extremo de uma ruptura radical e violenta da ordem legal, quando, através de sua presença ativa e criativa, os cidadãos desvendam e denunciam a distância política entre a nação "real" e a "legal", mas não reivindicam o poder de tomar as decisões.

Em um ensaio notável de 1789 sobre tipos de despotismo, Condorcet classificava a espécie de regulamentação arbitrária, passível de originar-se em um governo no qual a legislação resulta do consenso dos cidadãos em serem representados, como "despotismo indireto." O despotismo indireto "ocorre quando as pessoas não são mais verdadeiramente representadas ou quando ele [o corpo legislativo] se torna muito desigual' para elas ${ }^{20}$. Isso traz à tona os temas do mandato político e do vínculo de afinidade entre os eleitos e os cidadãos eleitores, dois componentes essenciais da representação política que não podem ser explicados dentro do contexto da política como vontade (e da democracia eleitoral), mas dependem muito do papel do juízo na deliberação política dentro e fora do órgão legislativo. No livro, analiso em detalhe os dois componentes da representação democrática, defesa e representatividade. Aqui, preciso

20. Marie-Jean Antoine Nicolas Caritat, marquês de Condorcet (1968, 9: 151-152) (grifos meus); uma idéia similar foi prenunciada por Locke, que descreveu como "usurpação" as situações nas quais legisladores eleitos "traíam seu mandato" e o soberano alterava "arbitrariamente" a práxis eleitoral, sem convocar novas eleições de modo a recompor o parlamento em acordo com o consentimento popular (Locke, The Second Treatise of Government, $\$ \S 222,216$ ). A idéia de que a democracia é caracterizada pelo "caráter continuamente responsivo do governo às preferências de seus cidadãos" é muito difundida entre os teóricos contemporâneos da democracia; Robert A. Dahl (1971: 1) (grifos meus); contudo, na ciência política contemporânea, a governabilidade (estabilidade do executivo) triunfa sobre a antecipação pelas eleições, de modo que o "caráter continuamente responsivo" significa, essencialmente, eleições regulares. 
simplesmente apontar para o fato de que a nova forma de arbitrariedade que o governo representativo está pronto a engendrar não é tirânica no sentido tradicional, pois ela não toma a forma de uma violação das regras constitucionais e normas legais. Essa é a razão pela qual o "despotismo indireto" não justifica formas violentas de rompimento com a ordem legal, ou meios excepcionais.

Ele justifica, entretanto, formas de prática política que sinalizem a necessidade de se superar a divisão interna à cidadania simbolicamente unificada. A linguagem do discurso político, como a do discurso moral, "deve ser suficientemente estável para que o que um homem diga realmente consista na tomada de uma posição, realmente diga-nos algo a seu respeito"; continuidade para além do período eleitoral é a norma que esperamos que os representantes sigam, de forma que possamos reconhecê-los, por assim dizer, ou julgá-los sempre, não somente ao final de seus mandatos 208 eleitorais. Uma vez que, ao aceitarem suas candidaturas, eles aceitaram submeter suas idéias e ações a nosso juízo, não cabe a eles sozinhos avaliarem a significância das posições que escolheram livre e responsavelmente tomar; "não cabe [a eles] sozinhos decidir se a reivindicação inicial [por eles] introduzida foi [por eles] adequadamente apoiada e elaborada" ${ }^{21}$.

Uma teoria democrática da representação deve ser capaz de explicar os eventos de continuidade bem como as crises e, além disso, envolver a idéia de que o povo soberano conserva um poder negativo que lhe permite investigar, julgar, influenciar e reprovar seus legisladores. Esse poder é negativo por duas importantes razões: sua finalidade é deter, refrear ou mudar um dado curso de ação tomado pelos representantes eleitos; e ele pode ser expresso tan-

21. Hanna Fenichel Pitkin (1885: 236) (grifos meus). 
to por canais diretos de participação autorizada (eleições antecipadas, referendo, e ainda o recall*, se sensatamente regulado, de modo que não seja imediato e, acima de tudo, rejeite o mandato imperativo ou instruções) quanto por meio dos tipos indiretos ou informais de participação influente (fórum e movimentos sociais, associações civis, mídia, manifestações) ${ }^{22}$. Esse poder popular negativo não é nem independente da nem antitético à representação política. Além do mais, ele é um ingrediente essencial do desempenho democrático da representação, porque entranhado no próprio caráter face de Jano desta instituição, que tem uma face virada para o Estado e outra para a sociedade. A representatividade consiste, como veremos daqui a pouco, na norma em relação à qual o poder negativo dos cidadãos pode ser descrito tanto como uma força revigorante quanto como um indicador que, à semelhança de um termômetro, sinaliza o status da "força integradora" que liga os eleitos e a assembléia que sedia a sociedade. Como oposto simétrico à comunicação enquanto "força socialmente integradora", o poder negativo dos cidadãos combina as normas de comunicação deliberativa (reciprocidade e publicidade) com a representatividade do representante.

Em suma, a teoria democrática precisa fazer retificações à concepção minimalista assim como à visão deliberativa habermasiana, de modo que se compreenda o mundo complexo da democracia representativa. Retificar a primeira, porque o foco na votação como resolução temporária do conflito político nos mostra a localização da "vontade" auto-

\footnotetext{
* Cassação do mandato por voto popular [N.T.]

22. Conforme exposto no último capítulo do livro, Condorcet foi o primeiro autor a conceber mecanismos institucionais para se reparar a interrupção da atuação responsiva, tais como o recall (sob certas circunstâncias e condições), eleições antecipadas e referendos; estes procedimentos destinavam-se a institucionalizar o poder negativo dos cidadãos (o "direito à reprovação") ou o direito de intervir quando quer que houvesse uma crise de representatividade.
} 
rizada a legislar, mas não nos fornece um retrato completo do jogo democrático que põe aquela vontade em movimento e a forma. Retificar a última, porque o foco na "força integradora da comunicação" joga luz insuficiente sobre a refrega política, que a representatividade da representação traz à tona, uma característica que é sempre uma questão de grau e flutuação, e uma construção ideológica que está sempre aberta à revisão e à reavaliação.

\section{A presença por meio do discurso e das idéias}

"Uma população de eleitores não é capaz por si mesma de iniciativa, mas, no máximo, de consentimento"; todavia, uma democracia representativa não é uma "massa de eleitores inorgânicos" e seus cidadãos são capazes de tomar iniciativas diretas e indiretas ${ }^{23}$. A representação política invalida a opinião de que a sociedade é a soma de indivíduos dissociados que competem e se unem, votam e agregam prefe-

210 rências por atos discretos de livre escolha e cálculo instrumental. Ela se contrapõe a uma concepção da democracia como uma multidão numérica de unidades singulares ou associadas forçadas a delegar seu poder pela simples razão de que uma multidão não pode ter uma vontade, não pode exercer nenhum poder ou ser um governo. Uma política representacional concebe a sociedade democrática como uma malha intrincada de significados e interpretações das crenças e opiniões dos cidadãos a respeito de quais são seus interesses; crenças que são específicas, diferenciadas e sujeitas à variação ao longo da vida real das pessoas. A democracia é única porque extrai das diferenças a força para a união ("as pessoas são capazes de se unir na diferença, sem se abstraírem de suas diferenças” ${ }^{24}$.

23. Augustine Cochin (1979: 80-81).

24. Charles Taylor (1998: 153). 
Na política representativa, diferentemente da democracia direta, os eleitores não são meras quantificações. Eles espelham a complexidade de opiniões e de influência política, nenhuma das quais é uma entidade computável aritmeticamente. Quando traduzimos idéias em votos, tendemos às vezes a nos esquecer dessa complexidade e assumir que os votos refletem preferências individuais, ao invés de representarem opiniões. Muito da argumentação de que a agregação de votos não esgota a expressão da opinião é familiar aos críticos da teoria da escolha social. Contudo, algumas observações adicionais podem ser reunidas para se alterar a leitura da votação democrática como uma participação que se presta a selecionar não políticas, mas tomadores de decisão.

Contrariamente aos votos sobre questões isoladas (democracia direta), um voto em prol de um candidato reflete a longue durée e efetividade de uma opinião política ou de uma constelação de opiniões políticas; ele reflete a atratividade de uma plataforma política, ou um conjunto de demandas e idéias ao longo do tempo (a democracia representativa tem sido então considerada um regime de tempo) ${ }^{25}$. O voto direto (ou, nas palavras de Condorcet, a "democracia imediata”) não cria um processo de opiniões e não permite que elas se baseiem em uma continuidade histórica, pois faz de cada voto um evento absoluto e, da política, uma série única e discreta de decisões (soberania pontuada). Mas quando a política é programada de acordo com os termos eleitorais e as políticas incorporadas pelos candidatos, as opiniões compõem uma narrativa que vincula os eleitores através do tempo e do espaço e faz das causas ideológicas uma representação de toda a sociedade e de seus problemas. Isso explica

25. Pierre Rosanvallon(2000: 62, 49); para uma excelente análise de dois modos de se interpretar o voto - seja como transcrição de interesses ou de opiniões políticas — veja Jeremy Waldron (1990: 49-51). 
por que as opiniões nunca têm peso igual, nem mesmo no caso hipotético de duas opiniões diferentes recebendo o mesmo número de votos. Se o peso das opiniões fosse igual, a dialética das opiniões e o próprio voto fariam pouco ou nenhum sentido. $\mathrm{O}$ voto é uma tentativa de se dar peso às idéias, não de torná-las idênticas quanto ao peso, ou com algum peso $^{26}$.

Pode-se, portanto, dizer que a democracia representativa revela o trabalho "miraculoso" das opiniões e narrativas ideológicas de uma forma que a democracia direta não é capaz, pois ela nos compele a transcender o ato de votar, num esforço de se reavaliar repetidamente a correlação entre o peso das idéias e o peso dos votos (na preservação, obtenção ou aumento do consentimento). Na democracia direta, todo voto é como um novo começo (ou uma resolução final) porque corresponde simplesmente à contagem de vontades ou preferências, mas não é nem pode ser repre212 sentativo das idéias; esperar pela "próxima oportunidade" não faz sentido, já que nela toda decisão é absoluta, porque torna as opiniões idênticas às vontades e carece de qualquer vínculo histórico com as cadeias de opiniões e decisões passadas e futuras.

Esta é a razão por que o voto direto em uma matéria não é uma alternativa à guerra civil, mas, na realidade, aumenta o risco de guerra civil e por que, de outro lado, a política representativa é um fator de estabilidade. Em uma democracia representativa, a cadeia de opiniões, interpretações e idéias que buscam visibilidade através da votação em um candidato ou partido consolida a ordem política - a divergência se torna um fator de estabilidade, um mecanismo de todo o processo político. Ela torna-se o liame que mantém unida uma sociedade que não possui centro visível e que

26. Antonio Gramsci (1973: 1.625); mas veja também John Dewey (1969: 232-233); e Ronald Dworkin (2000: 207). 
vem a se unificar por meio da ação e do discurso (experiências comuns de interpretação que os cidadãos compartilham, narram, resgatam e refazem incessantemente, na condição de partidários-aliados). Como Paine compreendeu, as opiniões e as crenças podem converter o poder em um processo político incessante ao qual a representação dá efetividade, pois enaltece o mundo público das idéias e a mediação do discurso, ambos os quais tornam nossos votos mais significativos do que uma porção infinitesimal da vontade geral. De modo bem eficaz, Claude Lefort salientou a natureza não-fundacional da democracia moderna (leia-se representativa), a qual "em virtude do discurso...revela que o poder a ninguém pertence; que aqueles que exercem o poder não têm domínio sobre ele; que eles, de fato, não o personificam; que o exercício do poder requer uma contestação repetida e periódica; que a autoridade daqueles investidos de poder é criada e recriada como resultado da manifestação da vontade do povo" ${ }^{27}$.

A representação política ilumina e enfatiza a natureza quérula da democracia. Na República, Platão descreveu (e criticou) a democracia não somente como um sistema de igualitarismo nivelador cego à especificidade individual, no qual operam a seleção por sorteio e a alternância de cargos ao invés da admissão dos competentes por alocação funcional. Na descrição de Platão, a democracia é primeiramente, e acima de tudo, um sistema no qual todos os cidadãos discordam quanto ao controle do governo porque todos eles reivindicam voz ativa no trato e resolução desse desacordo. Contudo, da mesma forma que a participação na eleição, a alternância e o sorteio dissipam algumas discordâncias, mas não silenciam a disputa entre os cidadãos. Mas por que os cidadãos disputam entre si, se sabem de antemão que irão

27. Claude Lefort (1988: 225). 
todos governar em algum momento ou terão outra chance de ter seus representantes eleitos e seu partido apoiado pela maioria? ${ }^{28}$

Os teóricos da democracia superestimam a escolha das pessoas e subestimam, por assim dizer, a escolha de políticas e idéias que a escolha das pessoas indica ou representa ${ }^{29}$. O caráter da competição democrática é, entretanto, moldado não apenas pelas regras do jogo, mas também pelos meios utilizados pelos cidadãos para expressar e resolver seus desacordos - qual seja, o discurso - independentemente de sua presença ser direta ou eleitoral ${ }^{30}$. Não por acaso, escritores clássicos que descreviam a democracia ateniense realçaram que todos os cidadãos possuíam uma chance igual não apenas de competir pelo poder, mas também de propor leis e conquistar a maioria na ekklesia. A crítica de Pseudo-Xenofonte à constituição de Atenas, em nome da competência aristocrática, é o primeiro documento relevante a atacar a 214 democracia por empregar o sorteio e a alternância a todos os cidadãos indistintamente, não apenas aos melhores dentre eles ou aos de mesma estirpe. Um sistema de governo no qual os iguais são tratados igualmente não é necessaria-

28. Platão (1983: 305).

29. Na Inglaterra pré-eleitoral, por exemplo, quando os postos parlamentares eram distribuídos entre os nobres como um reconhecimento de honra, o sorteio - não as eleições - era utilizado para se designar os candidatos, porque consistia em um sistema neutro que não permitia o julgamento ou a discriminação entre os pares (Kishlansky, 1986: 36).

30. Esta é a razão pela qual a concepção minimalista da democracia é deficiente. Ao passo que intelectualmente elegante, a idéia de democracia hobbesiana (busca da paz) não pode ser verdadeiramente minimalista. Sua ambição é ser apenas "descritiva", de modo a ser tão universalizável quanto possível. O problema é que, enquanto ele sustentar que mantém fatores não-minimalistas - tais como deliberação e participação - fora da definição e reduzir a democracia a um conjunto de normas regulando a expressão e solução temporária das "forças políticas conflitantes", o "minimalismo" não pode manter-se fiel sem presumir, sub-repticiamente, a participação e a deliberação dos cidadãos, sem as quais tanto a existência das "forças políticas conflitantes" quanto a manifestação de seu conflito seriam inconcebíveis. 
mente democrático, ainda que seja certamente igualitário. Isto é, por exemplo, o que distingue Atenas de Esparta e a razão pela qual a primeira, em vez da última, era conhecida como uma democracia, embora ambas utilizassem o sorteio e a alternância para selecionar magistrados, requeressem a presença direta dos cidadãos na assembléia e, finalmente, restringissem a cidadania a um consórcio relativamente pequeno de homens nativos adultos e livres.

É interessante notar que Rousseau (um admirador de Esparta) desdenhava, pelo mesmo motivo, tanto a democracia representativa quanto a direta, pois ambas, uma vez que empregavam o discurso como uma forma de ação política (ou de um modo indireto), tinham que se valer da competição para conquistar o consenso (fosse diretamente com relação às questões ou em relação a um candidato). Em sua mente, isso fazia da política democrática um experimento permanente de opiniões e formação de consenso, no qual a retórica e o juízo valorativo - não a presença por si ou a vontade - seriam essenciais. Ainda mais interessante é o caso de Hobbes, que não acreditava que as democracias eleitoral e direta fossem fundamentalmente diferentes e que apenas a primeira tivesse um caráter aristocrático. Hobbes compreendeu que a democracia é sempre uma mistura de igualdade e aristocracia, de tal modo que ela consiste tanto no igual direito de voto como também no igual direito de fala; e o discurso é o veículo para a distinção individual, a pluralidade e a altercação que a eleição regula ${ }^{31}$.

\section{0 partidarismo como uma representação ativa do geral}

A democracia é um "conflito delimitado" ou um "conflito sem assassinato": não é consenso ${ }^{32}$. Todavia, para que este

31. Thomas Hobbes (1994: 120). Discuti este assunto em "Representation as Advocacy: A Study of Democratic Deliberation”, Political Theory 28 (2000): 758-786.

32. Przeworski (1998: 49). 
seja o caso, os cidadãos devem consentir com certos valores ou princípios, e os vencedores e perdedores devem confiar que seus adversários irão abrir mão das armas independentemente do resultado das eleições. Seria, portanto, mais correto dizer que a democracia (na medida em que funcione e perdure) requer algum consenso básico porque diz respeito à divergência e também ao raciocínio instrumental. Não importa o quão mínima a definição de democracia, o minimalismo parece vir ao final de um processo mais ou menos bem sucedido, que as pessoas tenham elas mesmas encampado $^{33}$. O raciocínio instrumental e estratégico é suficientemente sofisticado para consistir em uma racionalização posterior de uma mais ou menos problemática experiência (de tentativa e erro) de aprendizado pela prática - parafraseando-se uma máxima pragmatista ${ }^{34}$.

Não é novidade dizer que, embora os procedimentos possam conter a desordem social, sua eficácia é amplamen216 te dependente de fatores éticos ou culturais. Isso é verdadeiro particularmente no caso da representação, pois o mandato que amarra o(a) representante à sua consistência é essencialmente voluntário; não é legalmente vinculativo. A representação consiste em uma práxis política que "não é meramente a realização arbitrária de escolhas, nem meramente o resultado da barganha entre ambições privadas, separadas" ${ }^{5}$. O raciocínio instrumental e o compromisso ocorrem em um contexto de entendimento comum acerca da direção política que o país deveria ou não tomar, com

33. "O fato de que concordamos sobre como casos particulares devam ser decididos... mostra... que os membros da comunidade fazem valer um conjunto de critérios comum. Sem critérios, tácitos ou explícitos, nossos veredictos seriam no conjunto inconsistentes e em desacordo com os veredictos de outros membros da comunidade... Logo, a possibilidade de se participar do jogo depende, em última instância, do fato bruto de que concordamos" (Elgin, 1999: 63).

34. Cf. John Dewey (1991: 175-184).

35. Pitkin (1967: 212). 
a consciência de que este "não é uma realidade que nos seja objetivamente dada de uma ou outra forma" ${ }^{36}$. Nestas condições, tal raciocínio é capaz de distinguir o inimigo total do partidário político, "a munição da eleição”*, para parafrasear Malcom X. A maior parte do tempo, sistemas de crenças e mesmo valores estereotipados estruturam a barganha e o raciocínio estratégico, de forma que, ainda que os eleitores possam parecer - ou honestamente tentar - raciocinar estrategicamente, eles acabam votando "contra" ou "a favor de" constelações de idéias e crenças quando votam em um candidato individual ${ }^{37}$.

John Rawls descreveu a "profundidade" e a "amplitude" de um consenso sobreposto - o que Hegel chamaria de "éthos constitucional" - nos seguintes termos:

“...depois que um consenso constitucional está em vigor, os grupos políticos são forçados a participar do fórum público de discussão política e dirigir-se a outros grupos que não compartilham sua doutrina abrangente. Esse fato torna racional para eles se afastar do círculo mais restrito de suas próprias visões e desenvolver concepções políticas em cujos termos possam explicar e justificar suas políticas preferidas a um público mais amplo, de modo a reunir uma maioria à sua volta" ${ }^{38}$.

\footnotetext{
36. Frank R. Ankersmit (1997: 47). Contudo, Ankersmit termina dizendo que o que torna a representação superior à democracia direta é o fato de que, uma vez que "inexiste uma proposta para a ação política da parte das pessoas representadas", seria equivocado esperar que as pessoas pudessem fazer propostas; "precisamos da representação para que sejamos capazes de definir estas propostas mesmas". Minha visão da representação como um processo de circularidade e circuito (entre as instituições e a sociedade) ambiciona não ser um neo-elitismo.

* No original: "the bullet and the ballot" [NT.].

37. A respeito da relevância do sistema de crenças na formação das preferências dos eleitores e do partido como um pólo de identificação, ao invés de uma simples máquina eleitoral, ver Adam Przeworski (1998: 143-144).
}

38. John Rawls (excerto retirado da edição brasileira, 2000: 212 [N.T.]). 
Os partidos políticos articulam o "interesse universal" a partir de pontos de vista periféricos. Eles são associações parciais-contudo-comunais e pontos essenciais de referência que possibilitam aos cidadãos e representantes se reconhecerem uns aos outros (e aos demais) e formarem alianças e, além disso, situarem ideologicamente os compromissos que estão prontos a estabelecer ${ }^{39}$. "Mas, de fato, uma das características mais importantes do governo representativo é sua capacidade para a resolução das demandas conflitantes das partes, com base em seu interesse comum no bemestar do todo" ${ }^{40}$. A dialética entre as partes e o todo explica a função complexa do arranjo legislativo em um governo representativo, como um órgão mediador entre o Estado e a sociedade ${ }^{41}$. A representação é a instituição que possibilita à sociedade civil (em todos os seus componentes) identificar-se politicamente e influenciar a direção política do país. Sua natureza ambivalente - social e política, 218 particular e geral - determina sua ligação inevitável com a participação.

A representação política transforma e expande a política na medida em que não apenas permite que o social seja traduzido no político; ela também promove a formação de grupos e identidades políticas. Acima de tudo, ela

\section{Z. A. Pelczynski(1964: 91).}

40. Pitkin, 1967: 217. Friedrich sugeriu que enfatizar o vínculo da representação com a sociedade ao mesmo tempo em que se separem as atividades políticas informais dos cidadãos da autorização eleitoral implica em "influência" ao invés de "participação": "Falamos advertidamente de influência em vez de participação ou controle, já que a maior parte dos cidadãos não está propensa a participar na ou efetivamente controlar a ação governamental" através da representação política; Carl J. Friedrich (1968: 278).

41. Esta concepção foi prefigurada em sua totalidade por Burke e Hegel, que usaram quase as mesmas palavras para descrever a função mediadora das instituições representativas, embora o último tenha enxergado melhor do que o primeiro o papel dos partidos políticos no governo constitucional e destacado a distinção crucial entre "facções" e "partidos"; veja-se, respectivamente, Burke, "Speech on Economical Reform” (1999: 160), e Hegel, "The English Reform Bill” (1964: 295-330). 
modifica a identidade do social, uma vez que, no momento em que as divisões sociais se tornam políticas ou adotam uma linguagem política, elas adquirem uma identidade na arena pública de opiniões e tornam-se mais inclusivas ou representativas de um espectro mais largo de interesses e opiniões. Isso é necessário para que elas conquistem uma maioridade numérica. Todavia, a estratégia é apenas uma explicação parcial. É próprio ao processo político de representação filtrar e dar conta da parcialidade irredutível das identidades sociais e culturais, tornando-as matérias de alianças e programas políticos. Isso faz dele precisamente o oposto da representação corporativista, advogada por teóricos da "participação de grupo", e da democracia do gerenciamento pluralista ${ }^{42}$. A pressuposição implícita de um modelo de democracia na forma de "pequenas unidades descentralizadas" (individuais ou coletivas) buscando representação direta na arena política é a idéia de que "a co-presença dos sujeitos em proximidade" deve purificar a política da manipulação ideológica levada a cabo pelos partidos. O resultado, entretanto, é que, ao se passar por cima do mundo mediado da "voz e do gesto, do espaçamento e da temporalidade", a política é "afastada" ao invés de purificada ${ }^{43}$.

Mas o partido político traduz as várias instâncias e particularidades em uma linguagem que é geral e tenciona representar o geral. Nenhum partido diz representar apenas os interesses daqueles que a ele pertencem ou o apóiam. O partidarismo é uma manifestação ativa do geral em vez de

\footnotetext{
42. Duas tradições formam a raiz da mistura de democracia com representação corporativa: a teoria da democracia forte e a teoria do socialismo de guildas e da democracia pluralista. Para um panorama crítico destas duas tradições veja Frederick M. Barnard (2001).

43. Iris Marion Young (1990: 233). Já desde James Madison, a idéia de que grupos partidários são constitutivos da democracia representativa tornou-se um tópos na teoria e na ciência políticas.
} 
uma apropriação do geral por um particular; é o oposto do patrimonialismo. Por isso pôde Hegel escrever que a representação traz o dissenso para a política porque, ao politizar a esfera social, ela traz a pluralidade e a diferença para dentro do público, e Weber pôde acentuar que o aspecto político do voto reside na chance que têm os cidadãos de transcender seu ser social pelo seu próprio fazer, o que equivale a dizer que agem independentemente de sua identidade social e tornam-se eles mesmos representantes de sua comunidade política ${ }^{44}$.

Pode ser útil recapitular o diagnóstico presciente de Tocqueville sobre as duas formas de associações democráticas que os cidadãos tendem a criar: associações civis, que reúnem (e dividem) os indivíduos de acordo com seus interesses ou opiniões específicos e, a maior parte do tempo, unidimensionais; e associações partidárias, que reúnem (e dividem) os cidadãos ao longo das linhas de suas interpre220 tações avaliativas de problemas que são gerais, ou de "igual importância para todas as partes do país.” As primeiras produzem uma fragmentação "ad infinitum sobre questões de detalhe" que raramente conseguem ser de alcance geral, uma vez que a vida das associações civis depende do relativo fechamento de seus limites. As últimas interrompem a fragmentação, não, contudo, pela imposição de uma homogeneidade ou ocultação da diferença (que coloque a sociedade inteira na imagem de um partido), mas pela criação de novas formas de "diferença" entre os cidadãos. O partidarismo político tanto congrega as pessoas quanto as separa

44. George Wilhelm Friedrich Hegel (1967, § 303); Max Weber (1994: 57-59). Daí Franco ter escrito que Hegel exibe "uma ambivalência similar" a Burke no tocante à representação, "certas vezes argumentando que o dever do representante é defender [...] o interesse nacional, em outras sustentando que é preservar os verdadeiros interesses de seu eleitorado em oposição às suas opiniões efêmeras" (Franco, 1990: 327). 
com relação a questões que são gerais em suas riqueza e implicações ${ }^{45}$. A função dos partidos vai muito além daquela instrumental, de provimento de organização e recursos para a alternância dos quadros políticos e a resolução pacífica dos pleitos por sucessão. Sua função é acima de tudo aquela de "integração da multidão", unificando as idéias e interesses da população e tornando o soberano permanentemente presente como um agente de influência e supervisão extra-estatais ${ }^{46}$.

Está além do escopo deste artigo analisar o papel da forma partidária de participação na democracia moderna, sua transformação de uma organização de notáveis, passando por uma instituição de massas e totalizadora, unificada por um credo político de tipo religioso, até um maquinário eleitoral que conta com a mídia, os analistas políticos e o dinheiro privado ${ }^{47}$. O questionamento crítico dos problemas que a liderança de grupo coloca para a democracia e a discussão do argumento weberiano de que a política representativa enseja a proletarização da massa por uma elite organizada e organizacional requereria um tipo de pesquisa bastante diverso. É suficiente notar aqui que a declaração da crise da ideologia e a decorrente virada cognitivista que a teoria do

45. Alexis de Tocqueville (1969: 174-175). Antecipando a distinção de Max Weber entre o partido ideológico e o partido de funcionamento eleitoral, Tocqueville distinguiu os "grandes partidos políticos" dos "partidos pequenos" e sugeriu que, enquanto os últimos agregam interesses "sem credo político", os primeiros unem os cidadãos por meio de princípios e interpretações acerca do destino geral do país. Tocqueville não sustentou que os interesses privados operem apenas em "partidos pequenos", embora tenha notado que em "grandes partidos políticos" os interesses "escondem-se por baixo do véu do interesse público." Similar à divisão de Tocqueville e uma antecipação da de Weber foi a distinção de Hegel entre hommes d'état e hommes à príncipes, a qual prefigurava duas formas diferentes de partidos (Hegel, 1964: 325; Weber, 1994: 152-154).

46. Friedrich(1963: 509-523).

47. Para um panorama histórico e analítico dos partidos (em oposição às facções e à democracia de massas como uma agregação atomista) na política moderna, veja Leon D. Epstein (1986, caps. 1-3). 
discurso conferiu à democracia são largamente responsáveis pelo silêncio e pela miopia da teoria política contemporânea a respeito do lugar do partido e do partidarismo na política democrática ${ }^{48}$. Todavia, a crise dos partidos ideológicos como os da Guerra Fria mostrou que a fragmentação pré-eleitoral - candidatos sem partidos - pode ser a origem de espécies ainda mais endêmicas de radicalismo ideológico ao invés de sinal de uma participação mais democrática e livre de preconceitos. Livres das antigas identificações ideológicas, os eleitores podem se achar capturados por e sob o extraordinário poder de outros tipos de potentados, tais como tribos étnicas e comunidades religiosas, magnatas da mídia privada e filiações comunitárias que, em vez de auxiliarem na deliberação, não se misturam ou criam compromissos arraigados ${ }^{49}$.

Mas a seleção de candidatos na condição de competidores isolados, sem um partido ou filiação a um grupo polí222 tico, não pode ser considerada um ideal de representação democrática, na medida em que pode inclusive se tornar um "afastamento dos princípios do governo representativo" 50 . $\mathrm{Na}$ realidade, se a eleição fosse de fato uma seleção entre e de candidatos isolados - entre e de nomes individuais ao invés de nomes de grupos políticos - a representação iria

48. Sem dúvida alguma, Habermas é o principal autor da versão cognitivista da deliberação e da liberdade democrática. Em uma crítica muito perspicaz a alguns de seus trabalhos, Quentin Skinner discutiu a forma como Habermas afasta-se das teorias clássicas da existência social como uma fonte da ausência de liberdade individual (de Weber até Foucault), ao atribuir a responsabilidade por nossa perda de liberdade "não primariamente" a "forças coercitivas externas", mas a "nós mesmos", ou porque nos falta conhecimento ou porque somos detentores de uma racionalidade "distorcida ideologicamente" (Skinner, 1982).

49. Muitas das dificuldades, recentemente atribuídas ao sistema representativo, de "levar em conta os pontos de vista" dos "infinitos grupos" com "posicionamentos não-uniformes" (Roberto Gargarella, 1998: 271) podem ser vistas como dificuldades relacionadas ao declínio da presença associativa do partido dentro da sociedade.

50. Manin (1997: 220), que julga que esta seja uma "mudança" em vez de um "afastamento" ou uma nova forma de seleção de elites. 
desaparecer, porque cada candidato(a) concorreria por si solitariamente e se tornaria, com efeito, um partidário de seu próprio interesse. $\mathrm{O}$ arranjo legislativo seria uma agregação de vontades individuais, mais ou menos como a assembléia na democracia direta - incapaz de tomar decisões por meio de um processo deliberativo estendido - e, ao final, não-representativo, já que apenas as idéias e opiniões (ou seja, o juízo em um sentido amplo) podem ser politicamente representáveis, não os indivíduos. Também por esta razão, a representação na esfera legislativa não corresponde simplesmente ao resultado das eleições. Melhor dito, ela é o resultado das eleições na medida em que ocorram dentro de um contexto político que envolva programas e idéias que sejam mais ou menos organizados e gerais, mas certamente capazes de atrair e unir os interesses e as idéias dos cidadãos (quer dizer, os seus votos). Votar no Sr. Smith sempre implica votar também no que o Sr. Smith diz e acredita, e assim, inevitavelmente, naquilo em que acreditamos e que defendemos ${ }^{51}$.

51. Norberto Bobbio (1996: 119-124); Kari Palonen (2004, n. ${ }^{\circ} 3:$ 114). Portanto, não é convincente que uma democracia pós-partidária ou "democracia de auditório" seja um estágio mais libertador. "A ascensão da mídia popular, não-partidária, tem uma conseqüência importante: quaisquer que sejam suas preferências partidárias, os indivíduos recebem a mesma informação do que todos os demais sobre um dado assunto. Os indivíduos certamente ainda formam opiniões divergentes sobre os assuntos políticos, mas a percepção do próprio assunto tende a ser independente da informação partidária do indivíduo" (Manin, 1997: 228-229). Contudo, a "democracia de auditório" exibe uma imagem um tanto diferente: aquela de uma reestruturação e remodelamento da forma partidária de acordo com objetivos e critérios que são menos, não mais, democráticos. No país que tornou o vídeo-populismo um poderoso desafio, contrário ao sistema partidário tradicional - a Itália - o Sr. Silvio Berlusconi foi capaz de conquistar uma maioria estável apenas quando criou seu próprio partido, endossou uma identidade ideológica forte e deu a seus eleitores a certeza de que eles pertenciam a um partido, não simplesmente a um comercial de televisão. Na superfície, a "democracia de auditório" parece sintetizar um sistema de representação que é fluido, aberto, caracterizado pela indeterminação e disputado por candidatos individuais em vez de membros partidários homologados. Uma análise mais detida, entretanto, revela que esse sistema é menos hierárquico, rígido e homologado do que seu antecessor, com a notável (e pejorativa) diferença de que neste caso o unificador é a pessoa do líder diretamente e o poder subliminar da mídia indiretamente. 
A representação política atesta o fato de que, embora a democracia possa ser explicada em termos de regras do jogo, a participação dos cidadãos não é um jogo neutro, mas uma forma concreta de se promover concepções e de se identificar com aqueles que as apóiam ou fazem alegações convincentes em sua defesa ${ }^{52}$. É por isso que a representação é "problemática" quando analisada em relação à democracia. Ela é problemática porque não pode nunca ser corroborada por e concebida nos termos de representantes que saibam efetivamente o que as pessoas desejam, e porque as expectativas das pessoas e as realizações de seus representantes jamais irão corresponder com exatidão ${ }^{53}$. Ao mesmo tempo em que desafia o cognitivismo, a representação democrática depende de muito mais do que simplesmente procedimentos eleitorais. Ela requer robustas autonomia local e liberdade de expressão e associação, bem como certa igualdade básica de condições materiais. Demanda também 224 uma cultura ética de cidadania que possibilite que tanto os representados quanto os representantes vejam as relações partidárias como não irredutivelmente antagonistas e sua defesa não como uma promoção incondicional de privilégios sectários contra o bem-estar de todos.

É, portanto, apropriado dizer que a compreensão da representação como uma instituição democrática, ao invés de um recurso ou uma segunda alternativa, coincide com a reabilitação de uma dimensão ideológica inevitável da polí-

52. Daí ter George Kateb (1983: 130-142)observado que enquanto o indivíduo é a unidade da obrigação legal, o(s) grupo(s) político(s) são as unidades que criam o consentimento em relação à lei.

53. Isso torna a accountability [prestação de contas dos governantes sobre seus atos (N.T.) ] (dos representantes para com os eleitores) uma demanda estruturalmente ética e política. Os teóricos do minimalismo democrático usam esse argumento para concluir que a única instituição verdadeiramente democrática é a eleição, pois os votos são os mais confiáveis dados públicos a nosso dispor e a votação é o único meio formal que têm os cidadãos para punir e ameaçar seus governantes. (Przeworski, 1999: 34-35) 
tica. Isso porque a política, no contexto da representação, envolve um processo complexo de unificação-e-desunião dos cidadãos, que os projeta para uma perspectiva orientada para o futuro. A política mantém o soberano em moto perpétuo, por assim dizer, ao passo em que transforma sua presença em uma manifestação de influência política complexa e delicada.

\section{Nadia Urbinati}

é professora do Departamento de Ciência Política da Universidade de Columbia

\section{Bibliografia}

ANKERSMIT, Frank R. 1997. Aesthetic Politics: Political Philosophy beyond Fact and Value. Stanford: Stanford University Press.

BARNARD, Frederick M. 2001. Democratic Legitimacy: Plural Values and Political Power. Montreal: McGill-Queen's University Press.

BOBBIO, Norberto. 1996. "Il compito dei partiti politici". In: GRECO, Tommaso (ed.). Tra due repubbliche: Alle origini della democrazia italiana, Rome: Donzelli.

BÖCKENFÖRDE, Ernst-Wolfgang. 1991. State, Society and Liberty: Studies in Political Theory and Constitutional Law. Trad. J. A. Underwood. New York/ Oxford: Berg.

BURKE, 1999. "Speech on Economical Reform". In: KRAMNICK, Isaac (ed.). The Portable Edmund Burke. London: Penguin.

CARITAT, Marie-Jean Antoine Nicolas (marquês de Condorcet). 1968. "Idées sur le despotisme”. 1789. In: ARAGO, M. F. e CONDORCET-O'CONNOR, A. (eds.). Oeuvres: Nouvelle impression en facsimilé de l'édition Paris 1847-1849. 12 volumes. Stuttgart-Bad Cannstatt: Friedrich Frommann. vol. 9: 151-152 .

CARRÉ DE MALBERG, Raymond. 1922. Contribution à la Théorie générale de l'État. Paris: Librairie Recueil Sirey. vol. 1: 231.

CLARKE, M. V. 1964. Medieval Representation and Consent: A Study of Early Parliaments in England and Ireland, with Special Reference to the Modus Tenendi Parliamentum. New York: Russell \& Russell.

COCHIN, Augustine. 1979. L'esprit du jacobinisme: Une interprétation sociologique de la Révolution française. Paris: Presses Universitaires de France.

DAHL, Robert A. 1971. Polyarchy: Participation and Opposition. New Haven: Yale University Press. 
1961. Who Governs? Democracy and Power in an American City.

New Haven: Yale University Press.

DEWEY, John. 1969. "The Ethics of Democracy”. In: BOYDSTON. J. A. (ed.). The Early Works, 1882-1898, vol. 1. Carbondale-Edwardswille: Southern Illinois University Press. 1991. The Public and Its Problems. Athens, Ohio: Swallow

Press/Ohio University Press.

DOWNS, Anthony. 1957. An Economic Theory of Democracy. New York: s.e.

DWORKIN, Ronald. 2000. Sovereign Virtue: The Theory and Practice of Equality. Cambridge: Harvard University Press.

ELGIN, Catherine Z. 1999. Considered Judgment. Princeton, NJ: Princeton University Press.

ELSTER, Jon. 1998. Deliberative Democracy. (Introdução). Ed. de Jon Elster. Cambridge: Cambridge University Press.

EPSTEIN, Leon D. 1986. Political Parties in the American Mold. Madison: The University of Wisconsin Press.

FRANCO, Paul. 1999. Hegel's Philosophy of Freedom. New Haven: Yale University Press.

FRIEDRICH, Carl J. 1963. Man and His Government: An Empirical Theory of Politics. New York: McGraw Book Company. . 1968. Constitutional Government and Democracy: Theory and Practice in Europe and America, Fourth edition. Waltham, Mass: Blaisdell.

GARGARELLA, Roberto. 1998. "Full Representation, Deliberation, and Impartiality”. In: ELSTER, Jon. Deliberative Democracy. Cambridge: Cambridge University Press.

GRAMSCI, Antonio. 1973. Quaderni del carcere. Turin: Einaudi.

HABERMAS, Jürgen. 1996. Between Facts and Norms: Contribution to a Discourse Theory of Law and Democracy. Trad. William Rehg. Cambridge: MIT Press. HEGEL, G. W. F. 1964. "The English Reform Bill”. In: Political Writings. Trad. T. M. Knox. Oxford: Clarendon Press.

1967. Philosophy of Right. Trad. T. M. Knox. Oxford: Oxford

University Press.

HOBBES, Thomas. 1994. "The Elements of Law Natural and Politic". In: GASKIN, J. C. A. (ed.). Human Nature and De Corpore Politico. Oxford: Oxford University Press.

KANTOROWICZ, Ernst. 1957. The king's two bodies. A study in mediaeval political theology. Princeton, NJ: Princeton University Press.

KATEB, George, 1983. Hannah Arendt: Politics, Conscience, Evil, Totowa, NJ: Rowman \& Allanheld.

KENNEDY, Ellen. 2004. Constitutional Failure: Carl Schmitt in Weimar. Dur- 
ham: Duke University Press.

KISHLANSKY, Mark A. 1986. Parliamentary Selection: Social and Political Choice in Early Modern England. Cambridge: Cambridge University Press.

LEFORT, Claude. 1988. Democracy and Political Theory. Trad. David Macey. Cambridge: Polity Press.

MANIN, Bernard. 1997. The Principles of Representative Government. Cambridge: Cambridge University Press.

PALONEN, Kari. 2004 "Parliamentarism: A Politics of Temporal and Rhetorical Distances”. In: SCHOBER, Anna (ed.). Österreichische Zeitschrift für Geschichtswissenschaften, Ästhetik des Politischen. n. ${ }^{\circ}$ 3: 114, volume especial. PELCZYNSKI, Z. A. 1964. Hegel's Political Writings (Introduction). Trad. T. M. Knox. Oxford: Clarendon Press.

PITKIN, Hanna Fenichel. 1967. The Concept of Representation. Berkeley: University of California Press.

1985. Wittgenstein and Justice: On the Significance of Ludwig

Wittgenstein for Social and Political Thought. Berkeley: University of California Press.

PLATÃO. 1992. Republic. Trad. G. M. A. Grube. Reeve. Indianapolis: Hackett. PRZEWORSKI, Adam. 1998. "Deliberation and Ideological Domination". In: ELSTER, Jon. (ed.). Deliberative Democracy. Cambridge: Cambridge University Press.

PRZEWORSKI, Adam. 1999. "Minimalist conception of democracy: a defense". In: SHAPIRO, Ian e HACKER-CORDÓN, Cassiano (ed.). Democracy's Value. Cambridge: Cambridge University Press.

RAWLS, John. 2000. Political Liberalism. New York: Columbia University Press, 1993. In: O Liberalismo Político. Trad. Dinah de Abreu Azevedo. São Paulo: Ática.

ROSANVALLON, Pierre. 2000. La démocratie inachevée: Histoire de la souveraineté du peuple en France. Paris: Gallimard.

SCHUMPETER, Joseph A. 1962. Capitalism, Socialism and Democracy. New Yok: Harper Torchbook.

SKINNER, Quentin. 1982. "Habermas1s Reformation". The New York Review of Books, 7, outubro 1982.

Press. vol. 3: 185.

2002. Visions of Politics. Cambridge: Cambridge University

TAYLOR, Charles. 1998. “The Dynamic of Democratic Exclusion”. Journal of Democracy 9: 153.

TOCQUEVILLE, Alexis de. 1969. Democracy in America. Trad. J. P. Mayer. New York: Harper Perennial.

URBINATI, Nadia. 2000. "Representation as Advocacy: A Study of Demo- 
cratic Deliberation”. Political Theory 28: 758-86.

VILLENEUVE, Marcel De la Bigne de. 1929-1932. Traité générale de l'Etat. Paris: Sirey. Vol. 2: 32.

WALDRON, Jeremy. 1990. "Rights and Majorities: Rousseau Revisited". In: CHAPMAN, John W. e WERTHEIMER, Alan (ed.). Majorities and Minorities, Nomos XXXII. New York: New York University Press.

WALZER, Michael. 1983. Spheres of Justice: A Defense of Pluralism and Equality. New York: Basic Books.

WEBER, Max. 1994. Political Writings. Ed. de Peter Lassman e Ronald Speirs. Cambridge: Cambridge University Press.

YOUNG, Iris Marion. 1990. Justice and the Politics of Difference. Princeton, NJ: Princeton University Press. 


\section{( ) )}

\section{O QUE TORNA A REPRESENTAÇÃO DEMOCRÁTICA?}

NADIA URBINATI

A autora, seguindo passos já dados por Bernard Manin e outros, mas introduzindo suas próprias inquietações, faz uma reflexão sobre a natureza da representação democrática, mostrando sua originalidade como forma de governo representativo. Seu esforço teórico, nesse sentido, é apontar as diferenças desse modelo em relação à "democracia eleitoral”, por um lado, e à “democracia direta”, por outro.

Palavras-chave: Teoria Democrática; Governo representativo; Democracia direta; Democracia eleitoral.

\section{WHAT MAKES REPRESENTATION DEMOCRATIC?}

The author, following the steps of Bernard Manin and others, but presenting her own insights, discusses the nature of democratic representation, standing for its originality as a type of representative government. Her main theoretical point is to single out the distinctive features of that type from both the "electoral democracy" as well as the "direct democracy".

Palavras-chave: Democratic Theory; Representative government; Direct democracy; Electoral democracy. 